\title{
Acneform eruptions with use of minoxidil-a case report
}

\author{
Vardhan A ${ }^{1}, C$ Dinesh M Naidu ${ }^{2}$, Bankar $M^{3}$, Sharma $S^{4}, \operatorname{Raghuvanshi~} V^{5}$ \\ ${ }^{1}$ Dr. Anand Vardhan, Senior Resident, ${ }^{2}$ Dr. C Dinesh M Naidu, Professor, ${ }^{3}$ Dr. Mangesh Bankar, Associate Professor, \\ ${ }^{4}$ Dr. Sagar Sharma, Senior Resident, ${ }^{5}$ Dr. Vinay Raghuvanshi, Senior Resident, all authors are affiliated with Department \\ of Pharmacology, Andaman and Nicobar Islands Institute of Medical Sciences, Port Blair, India
}

Address for Correspondence: Dr Anand Vardhan, Email: varanand.26@ gmail.com

\begin{abstract}
A 32 year male patient resident of Andaman and Nicobar Islands presented to the dermatology OPD with the chief complaints of acneform eruptions since 1 month after the use of Minoxidil/Aminexil 5\% solution for the treatment of Alopecia which he had since 6 months. Diagnosis of androgenic alopecia was made based on the clinical examination and hence treatment with tablet Finpecia (Finasteride) $1 \mathrm{mg}$ once daily and 5\% Minoxidil/ Aminexil topical solution $1 \mathrm{ml}$ thrice daily local application was advised and patient was asked to come back for follow up after a period of 2 months, but the patient returned after 1 month of treatment with the complaints of comedonic eruptions on forehead.
\end{abstract}

Keywords: Minoxidil/ Aminexil Topical solution, Acneform eruptions

\section{Introduction}

In 1965 minoxidil was discovered as hypotensive agent. In 1968, group of investigators observed hypertrichosis in several hypertensive patients receiving oral minoxidil [1]. Topical minoxidil was first used for alopecia areata in 1981[2] and then for androgenetic alopecia [3]. It is usually a safe drug, except that a proportion of the topically applied drug gets absorbed through the skin and if the quantity of the drug applied is more, it can cause headache in the patient. This headache is dose dependent and disappears if the quantity of the drug applied on the skin is reduced. The other side effects are irritant dermatitis and increased hair growth in area of drug application. Contact dermatitis due to minoxidil has already been reported in eight cases [4,5]. The adverse effects of minoxidil can be severe and can be divided into different categories: salt and water retention, cardiovascular effects and hypertrichosis. Hypertrichosis occurs in the patients on minoxidil for an extended period and may be a consequence of potassium channel activation. Topical minoxidil is marketed over the counter for treatment of male pattern baldness. Topical use of minoxidil can also cause cardiovascular effects in some individuals. Other side effects are rare and include rashes, steven Johnson syndrome, glucose intolerance, serosanguinous bullae, and thrombocytopenia [6].

\section{Case Report}

A 32 year male patient resident of Andaman and Nicobar Islands presented to the dermatology OPD with the chief complaints of acneform eruptions since 1 month after the use of Minoxidil/Aminexil 5\% solution for the treatment of Alopecia which he had since 6 months. Diagnosis of androgenic alopecia was made based on the clinical examination and hence treatment with tablet Finpecia (Finasteride) $1 \mathrm{mg}$ once daily and 5\% Minoxidil/ Aminexil topical solution $1 \mathrm{ml}$ thrice daily local application was advised and patient was asked to come back for follow up after a period of 2 months, but the patient returned after 1 month of treatment with the complaints of comedonic eruptions on forehead. A patch test was done with powdered tablet of minoxidil and the patient had Hypersensitivity thus confirming the diagnosis. A Diagnosis of Contact Dermatitis was made by the physician and Topical betamethasone cream with oral antihistaminics

Manuscript received $20^{\text {th }}$ September 2016

Reviewed: $28^{\text {th }}$ September 2016

Author Corrected: $09^{\text {th }}$ October 2016

Accepted for Publication $20^{\text {th }}$ October 2016 
were prescribed. After 3 days of treatment the lesions started regressing and rechallenge with Topical Minoxidil 5\% solution was done. This time patient was instructed to apply Minoxidil once daily instead of thrice daily and the patient responded, this time no contact dermatitis was seen.

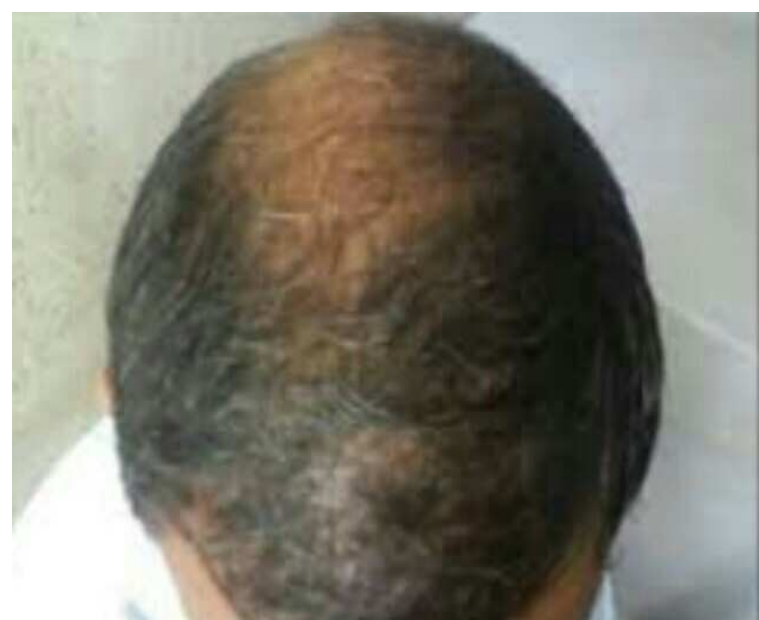

Fig-1: 32 year male patient with Alopecia (Picture taken at the time of first hospital Visit when Minoxidil was prescribed)

\section{Discussion}

Excessive applications of minoxidil lotion can sometimes cause non-specific irritant reactions, but contact dermatitis should be suspected if the patient reacts to normal or even smaller quantities of the drug. It is also necessary to exclude the possibility of contact hypersensitivity to some other constituent of the commercial solution rather than minoxidil itself. The commercial minoxidil has propylene glycol and ethyl alcohols as base and till now 4 patients have been recorded who were allergic to propylene glycol rather than minoxidil [7].

Pasricha JS et al in 1991 reported a case of contact dermatitis with minoxidil of a 25-year-old girl started having diffuse loss of hair from the fronto-parietal areas and she started applying a commercial hair lotion containing $2 \%$ minoxidil in an alcoholic base [8].

\section{Conclusion}

Therefore we conclude that this was a case of contact dermatitis caused by use of therapeutic doses of Minoxidil/Aminexil 5\% topical solution, the rechallenge with same topical solution was done with reduced dosage and no dermal reactions were observed.

Funding: Nil, Conflict of interest: None initiated, Permission from IRB: Yes

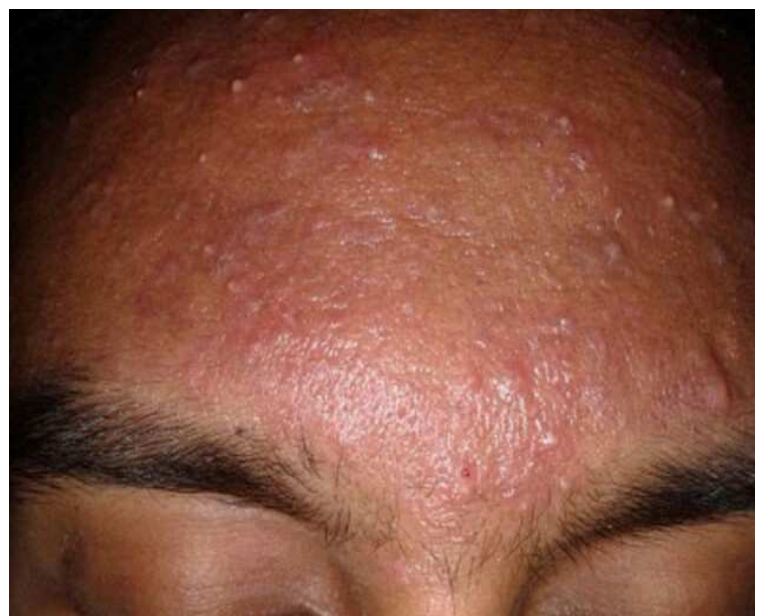

Fig-2: Acneform Eruptions (Allergic Contact

Dermatitis) after a month of Minoxidil use

\section{References}

1. Zin GR : The history of the development of minoxidil, Clin Dermatol, 1988:6:132-47.

2. Weiss VC, West DP and Mueller CE: Topical minoxidil in alopecia areata, J Amer Acad Dermatol, 1981; 5:224-6.

3. De Villez RL: Topical minoxidil therapy in hereditary androgenetic alopecia, Arch Dermatol, 1985; Feb;121(2):197-202

4. Degreef H, Hendricks 1 and Dooms-Goossens A: Allergic contact dermatitis to minoxidil, Contact Dermatitis, 1985; 13:194-5.

5. Fiedler-Weiss VC, West DP, Buys CM et al: Topical minoxidil dose-response effect in a alopecia areata, Arch Dermatol, 1986; 122:180-82

6. Laurance L. Brunton, Bruce A, Chabner, Bjorn C Knollmann. The pharmacological basis of Therapeutics in Goodman \& Gilman's ed12; 2011:778-81.

7. Van der Willigen AH, Dutree-Meulenberg ROGM, Stolz E et al: Topical minoxidil sensitization in androgenic alopecia, Contact Dermatitis, 1987; 17:44-5. 
8. Pasricha J S, Nanda A, Bajaj N. Contact dermatitis 1991;57(5):235-6 due to minoxidil. Indian $\mathbf{J}$ Dermatol Venereol Leprol

\section{How to cite this article?}

Vardhan A, C Dinesh M Naidu, Bankar M, Sharma S, Raghuvanshi V. Acneform eruptions with use of minoxidil-a case report. Int J Med Res Rev 2016;4(10):1761-1763.doi:10.17511/ijmrr. 2016.i10.08. 